\title{
Waste Feed from Fish Farms of the Eastern Mediterranean and Attraction of Wild Fish
}

\author{
N. Neofitou \\ Department of Ichthyology and Aquatic Environment, School of Agriculture, University of Thessaly, Greece
}

Copyright $(2016$ by authors, all rights reserved. Authors agree that this article remains permanently open access under the terms of the Creative Commons Attribution License 4.0 International License

\begin{abstract}
Fish are attracted to floating structures, including coastal cage fish farms, sometimes in dense aggregations. To understand the influence of aquaculture on wild fish stocks, three samplings were carried out by fishing bait and trammel netting around two Eastern Mediterranean farms. A total number of 54 individuals belonging to 12 species were captured. Striped mullet, salema and white trevally were the species that consumed pellets in great quantity. The results of this preliminary study indicates that feeding behavior of wild fish around fish cages can have important ecological consequences on reducing the environmental effects of aquaculture in Pagasitikos gulf.
\end{abstract}

Keywords Aquaculture, Pellets, Wild Fish, Mediterranean

\section{Introduction}

Intensive finfish aquaculture, as commonly practised in net pens in the Mediterranean Sea, involves the supply of high quality artificial feeds. This generates large amounts of organic wastes (uneaten food and faeces), which are directly released into the receiving environment [1]. This leads to attraction of wild fish aggregations in great biomass $[2,3,4]$ to feed upon this source $[3,5]$.

Several previous studies have investigated assemblages of wild fish associated with marine fish farms in the North European and Mediterranean temperate locations [6, $2,3,5,7,8]$. Nevertheless, only few of them have examined the stomach content of wild fish in order to determine the percentage of uneaten pellets that consumed by them $[3,5,6]$. No publication has addressed this topic in the Eastern Mediterranean. Furthermore, as the Mediterranean Sea is oligotrophic and fish populations are overexploited [9], any expansion of this industry will require research into how aquaculture and natural living resources interact. Therefore, the specific aims of this preliminary study in a semi-enclosed gulf of the Eastern Mediterranean were to investigate the temporal persistence of wild fish around coastal aquaculture and to study the diet of these fish in order to determine the percentage of uneaten pellets that consumed by them.

\section{Materials and Methods}

This preliminary study was carried out in Pagasitikos gulf which is located in the Western Aegean Sea (Eastern Mediterranean). Two marine fish farms were examined: The first (31 to $36 \mathrm{~m}$ depth) is situated at the southeast part of Pagasitikos ( $\left.39^{\circ} 07^{\prime} 38^{\prime \prime} \mathrm{N}, 23^{\circ} 09^{\prime} 17^{\prime \prime} \mathrm{E}\right)$; the second (28 to $38 \mathrm{~m}$ depth) is situated at the southwest part of Pagasitikos $\left(39^{\circ} 07^{\prime} 13^{\prime \prime} \mathrm{N}, 22^{\circ} 57^{\prime} 53^{\prime \prime} \mathrm{E}\right)$. These are henceforth referred to as AS and BS farm, respectively. Sea bream Sparus aurata and sea bass Dicentrarchus labrax are intensively cultured in these farms where they are fed both pelleted and extruded diets. At the time of the study, the average annual standing stocks were 130 and $92 \mathrm{t}$ for AS and BS farms, respectively.

This study applied two different sampling methods. One sampling was carried out at the AS farm by fishing bait and two samplings at the BS farm by trammel netting in order to catch wild fish under fish cages. The fishing bait at the AS farm was made in one day (in September) from the walkway of the cages, directly after the early feeding time. The trammel nettings at the BS farm were carried out in two nights (one in September and one in October) and the purpose of the sampling time was to catch as many wild fish around fish cages as possible. The net was 28 to $30 \mathrm{~mm}$ square mesh and hauls were made directly adjacent to cages and around the fish farm by lowering the net into the water using a fishing boat.

All fish were iced after landings and analysed in the same day. Individuals were identified, measured (TL) and weighed before and after removing the stomach contents (TW and NW). To study diet, their stomachs removed and the contents washed into Petri dishes for examination. The stomach contents sorted by hand under a stereomicroscope (Olympus SZX9, New York, USA) into two major categories (pellets and other food). These two major categories of food were dried at $60^{\circ} \mathrm{C}$ to constant weight and the amount of pellets in a stomach was calculated as the proportion rate of the total contents dry weigh [10]. 


\section{Results}

A total number of 23 individuals belonging to 6 species and 31 individuals belonging to 9 species were captured at the AS and BS farms, respectively (Table 1). Sea bass Dicentrarchus labrax, striped mullet Mugil cephalus and sea bream Sparus aurata were the common species of the two studied farms (Table 1). Among these species only striped mullet at the AS farm was captured with stomach full of pellets, while rest of them were caught with empty stomachs (Table 1 \& Figure 1). Furthermore, white trevally Pseudocaranx dentex and salema Sarpa salpa were captured with stomach full of pellets (AS farm), while in all other cases fish were caught with empty stomachs or without pellets (Table 1). White trevally $P$. dentex and common pandora Pagellus erythrinus were the most dominant species at the AS and BS farms, respectively (16 and 18 ind.; Table $1)$.

Table 1. Size, weight and stomach content analysis of wild fish captured around sea cages of the AS and BS farms

\begin{tabular}{|c|c|c|c|c|c|c|}
\hline Farm & Species & $n$ & $\mathrm{TL}(\mathrm{cm})$ & TW (g) & NW (g) & Pellets \% \\
\hline \multirow[t]{6}{*}{ AS } & Boops boops & 1 & $38.2(0.0)$ & $676.1(0.0)$ & $634.6(0.0)$ & + \\
\hline & Dicentrarchus labrax & 1 & $28.8(0.0)$ & $239.38(0.0)$ & $205.9(0.0)$ & + \\
\hline & Mugil cephalus & 1 & $41.0(0.0)$ & $687.3(0.0)$ & $582.4(0.0)$ & $100.0(0.0)$ \\
\hline & Pseudocaranx dentex & 16 & $33.1(1.3)$ & $361.1(35.2)$ & $342.2(34.1)$ & $98.5(1.5)$ \\
\hline & Sarpa salpa & 3 & $39.5(1.0)$ & $1001.1(68.8)$ & $898.1(64.2)$ & $100.0(0.0)$ \\
\hline & Sparus aurata & 1 & $26.8(0.0)$ & $301.4(0.0)$ & $284.6(0.0)$ & + \\
\hline \multirow[t]{9}{*}{$\mathrm{BS}$} & Dentex dentex & 1 & $29.1(0.0)$ & $337.2(0.0)$ & $325.0(0.0)$ & $0.0(0.0)$ \\
\hline & Dicentrarchus labrax & 2 & $31.8(1.4)$ & $356.1(49.5)$ & $312.9(37.8)$ & + \\
\hline & Diplodus sargus & 1 & $23.0(0.0)$ & $216.7(0.0)$ & $205.7(0.0)$ & $0.0(0.0)$ \\
\hline & Mugil cephalus & 2 & $50.1(1.8)$ & $1130.0(3.5)$ & 939.4 (45.9) & + \\
\hline & Mullus surmuletus & 4 & $18.6(0.6)$ & $86.1(9.3)$ & $79.7(8.9)$ & $0.0(0.0)$ \\
\hline & Pagellus erythrinus & 18 & $26.8(0.6)$ & $263.0(21.6)$ & 245.5 (18.9) & $0.0(0.0)$ \\
\hline & Sparus aurata & 1 & $26.7(0.0)$ & $308.7(0.0)$ & $290.8(0.0)$ & + \\
\hline & Torpedo torpedo & 1 & $29.4(0.0)$ & $547.2(0.0)$ & $457.2(0.0)$ & + \\
\hline & Uranoscopus scaber & 1 & $17.2(0.0)$ & $80.3(0.0)$ & $73.9(0.0)$ & $0.0(0.0)$ \\
\hline
\end{tabular}

Values in parenthesis are standard errors. $n$, number of individuals analysed; TL, total length; TW, total weight; NW, net weight; Pellets \%, percentage of pellets in the stomach content; +, empty stomach

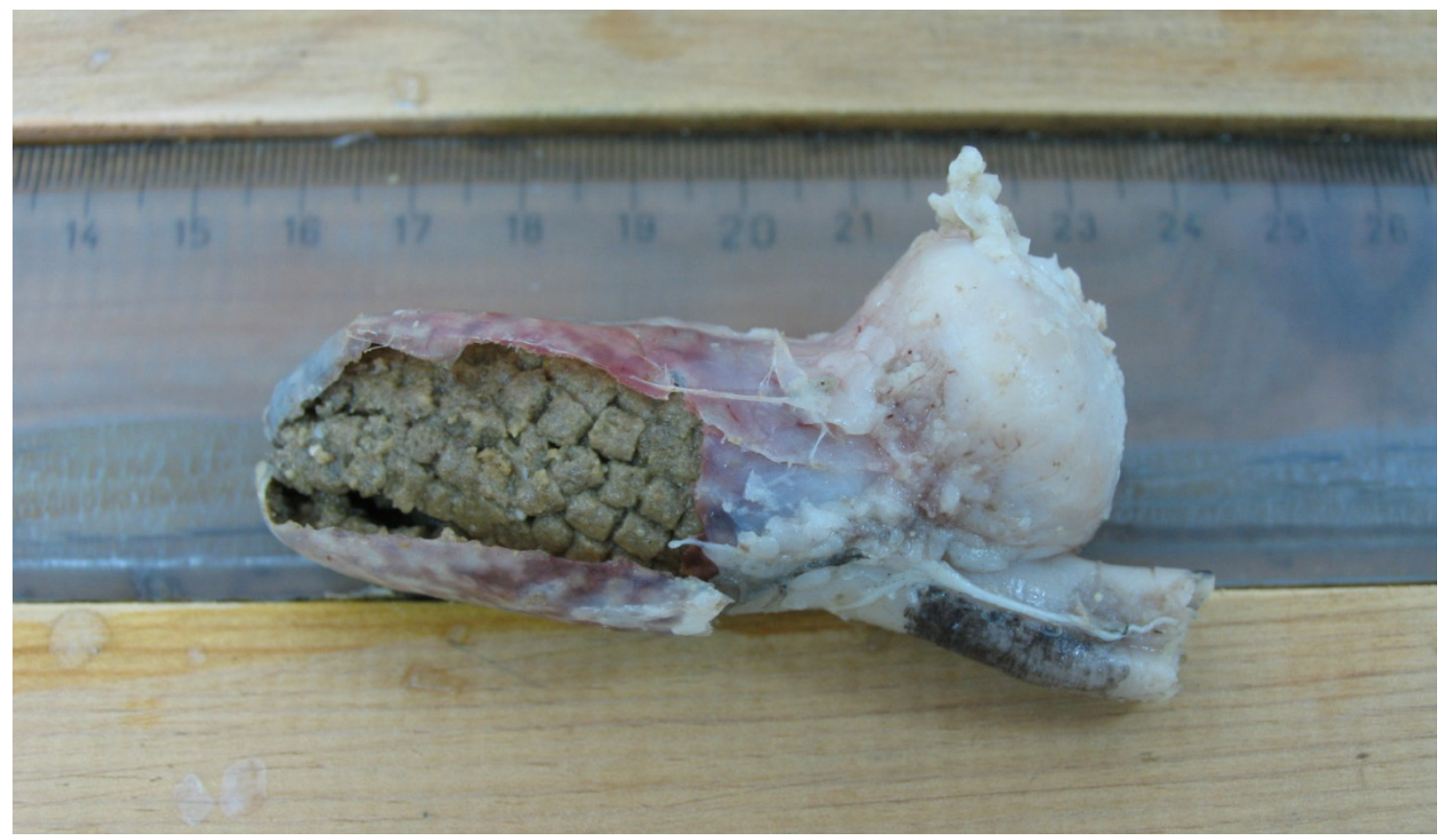

Figure 1. Stomach content of a Mugil cephalus captured at the AS farm, which was filled with pellets 
The stomach content analysis of wild fish captured around sea cages of the AS farm's indicated that $53 \%$ of these were fed exclusively on pellets, $4 \%$ were fed on a large proportion of pellets, while the rest $43 \%$ were empty of food (Figure 2 ). Furthermore, in the first netting sampling of the BS farm (September), stomach content analysis showed that $39 \%$ of wild fish were fed on natural food and the rest $61 \%$ of stomachs were empty, while in the second netting sampling of the BS farm (October) the percentages were 69\% and 31\%, respectively (Figure 2).

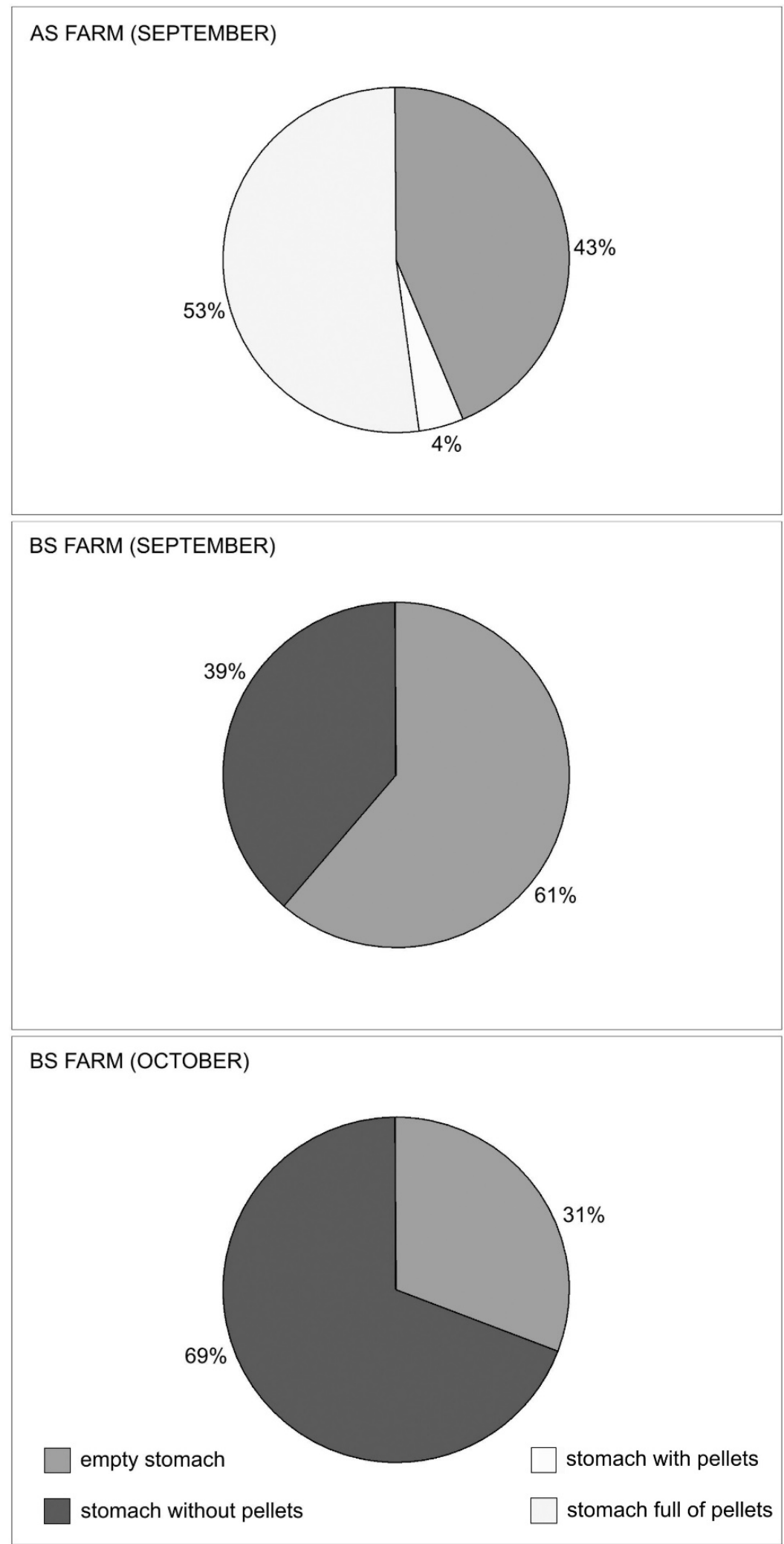

Figure 2. Stomach content analysis of wild fish around sea cage's over all samplings 


\section{Discussion}

This preliminary study demonstrates that sampling by fishing bait directly after the feeding time was the most appropriated method in contrast with trammel netting during the night since all the wild fish that captured with this method were fed on natural food or had an empty stomach. This finding may imply that pellets were digested until the night or that nets stressed fish causing them regurgitation [10]. In the Western Scotland, Carss [6] utilized beach-seine netting in order to catch wild fish around farm cages and to examine the stomach content for pellets, while a similar study in the Western Mediterranean employed spear fishing [3]. Furthermore, Carss [6] reported that catching efficiency of beach seines varies and is dependent on both study location and species and the catching efficiency can be increased for many species by keeping the lead lines of the net on the bottom at all times.

In the present preliminary study, we found 12 different species of fish associated with the two farms studied, belonging mainly to the Sparidae and Carangidae (75\% of the total captured fish). Combining this total number with similar observations from Fernandez-Jover [3], with seasonal visual censuses around three Western Mediterranean farms over 2 years, yields a total of 33 species, belonging mainly to the Clupeidae, Sparidae, Mugilidae and Carangidae.

The sea bass and sea bream that were captured around sea cages of the AS and BS farms thought to have escaped from the farms itself. Fish may escape during the grading or harvesting of stock and when nets are damaged by vandals or during storms. Many of them probably remain close to the cages because of the almost constant supply of food [6]. Nevertheless, it is paradox the fact that these two species were caught with empty stomachs. For the samplings at the BS farm this finding is maybe due to the regurgitation process but for the AS farm sampling it is not justified.

Striped mullet, salema and white trevally were the species that consumed pellets in grate quantity $(57 \%$ of the total captured fish at the AS farm). In previous studies, Fernandez-Jover [3], reported that Mugilids were the taxa that consumed pellets in greatest quantity, while Carss [6] reported that saithe was the most commonly caught of 21 species of non-salmonid wild fish and the only marine species found to have eaten pellet food. The feeding of wild fish around fish farms diminishes the total waste produced by the cages by $80 \%$ [1].

The results of this preliminary study contribute to an improved understanding of the methods that can be used in future research to investigate the temporal persistence of wild fish around coastal aquaculture and to study the diet of these fish. Furthermore, these preliminary results indicates that feeding behavior of wild fish around fish cages can have important ecological consequences on reducing the environmental effects of aquaculture in Pagasitikos gulf, which is in agreement with the results of previous studies in this region $[11,12]$.

\section{REFERENCES}

[1] R. Vita, A. Marin, J.A. Madrid, B. Jimenez-Brinquis, A. Cesar, L. Marin-Guirao. Effects of wild fishes on waste exportation from a Mediterranean fish farm. Marine Ecology Progress Series, 277: 253-261, 2004.

[2] T. Dempster, P. Sanchez-Jerez, J.T. Bayle-Sempere, F. Gimenez-Casalduero C. Valle. Attraction of wild fish to sea-cage fish farms in the south-western Mediterranean Sea: spatial and short-term temporal variability. Marine Ecology Progress Series, 242: 237-252, 2002.

[3] D. Fernandez-Jover, P. Sanchez-Jerez, J.T. Bayle-Sempere, C. Valle, T. Dempster. Seasonal patterns and diets of wild fish assemblages associated to mediterranean coastal fish farms. ICES Journal of Marine Science, 65: 1153-1160, 2008.

[4] T. Dempster, I. Uglem, P. Sanchez-Jerez, D. Fernandez-Jover, J. Bayle -Sempere, R. Nilsen, P.A. Bjorn. Coastal salmon farms attract large and persistent aggregations of wild fish: an ecosystem effect. Marine Ecology Progress Series, 385: 1-14, 2009.

[5] D. Fernandez-Jover, L. Martinez-Rubio, P. Sanchez-Jerez, J.T Bayle-Sempere, J.A. Lopez-Jimenez, F.J. Martinez-Lopez, P.A. Bjorn, I. Uglem, T. Dempster. Waste feed from coastal fish farms: A trophic subsidy with compositional side-effects for wild gadoids. Estuarine, coastal and shelf science, 91: 559-568, 2011.

[6] D. Carss. Concentrations of wild and escaped fishes immediately adjacent to fish farm cages. Aquaculture, 90: 29-40, 1990.

[7] A. Machias, I. Karakassis, M. Labropoulou, S. Somarakis, K.N. Papadopoulou, C. Papaconstantinou. Changes in wild fish assemblages after the establishment of a fish farming zone in a oligotrophic marine ecosystem. Estuarine Coastal and Shelf Science, 60: 771-779, 2004.

[8] M. Giannoulaki, A. Machias, S. Somarakis, I. Karakassis. Wild fish spatial structure in response to presence of fish farms. Journal of Marine Biological Association, 85: 1271-1277, 2005.

[9] FAO. The State of World Fisheries and Aquaculture. FAO, Rome. http://www.fao.org/docrep/009/a0699e/a0699e00.htm, 2007.

[10] L.A. Nielsen, D.L. Johnson. Fisheries Techniques. American Fisheries Society, Virginia, 1989.

[11] N. Neofitou, S. Klaoudatos. Effect of fish farming on the water column nutrient concentration in a semi-enclosed gulf of the Eastern Mediterranean. Aquaculture Research, 39: 482-490, 2008.

[12] N. Neofitou, D. Vafidis, S. Klaoudatos. Spatial and temporal effects of fish farming on benthic community structure in a semi-enclosed gulf of the Eastern Mediterranean. Aquaculture Environment Interactions, 1: 95-105, 2010. 